This item was submitted to Loughborough's Research Repository by the author.

Items in Figshare are protected by copyright, with all rights reserved, unless otherwise indicated.

\title{
Journey mapping from a crew's perspective: Understanding rail experiences
}

PLEASE CITE THE PUBLISHED VERSION

https://doi.org/10.1016/j.apergo.2020.103063

PUBLISHER

Elsevier

VERSION

AM (Accepted Manuscript)

PUBLISHER STATEMENT

This paper was accepted for publication in the journal Applied Ergonomics and the definitive published version is available at https://doi.org/10.1016/j.apergo.2020.103063

\section{LICENCE}

CC BY-NC-ND 4.0

\section{REPOSITORY RECORD}

Oliveira, Luis CR, Stewart Birrell, and Rebecca Cain. 2020. "Journey Mapping from a Crew's Perspective: Understanding Rail Experiences”. figshare. https://hdl.handle.net/2134/11871915.v1. 


\title{
Journey mapping from a crew's perspective: understanding rail experiences
}

Luis CR Oliveira L.Oliveira@warwick.ac.uk (Corresponding author) WMG, University of Warwick, Coventry, CV4 7AL, United Kingdom

Stewart Birrell Stewart.birrell@ coventry.ac.uk WMG, University of Warwick, Coventry, CV4 7AL, United Kingdom * * Current address:

Coventry University, Coventry, CV1 5FB, United Kingdom

Rebecca Cain R.Cain@lboro.ac.uk

Design School, Loughborough University, Loughborough, LE11 3TU, United Kingdom

\begin{abstract}
Technological developments present diverse opportunities to modernise services for the rail industry. Systems can be implemented to improve passengers' experiences, but these may also affect the experiences of crew working on board trains. This first-of-a-kind research extends the concept of customer journey mapping as a design tool to understand the experiences of train crew. To produce these crew journey maps, interviews and user observation methods were adopted $(N=22)$. Results show that two main negative touchpoints for the crew occur at the platform-train interface and during revenue protection activities. This paper presents an innovative methodological contribution around journey mapping to better understand rail experiences, but revolving around the crew rather than the expected consumer experience. We conclude this paper proposing requirements for technological systems and indicate opportunities for the design of systems to generate human-centred improvements for the working practices and experiences of train crew.
\end{abstract}

Keywords: customer journey map; qualitative study; shadowing; work satisfaction; user experience

\section{Introduction}

Recent technological developments present opportunities to enhance experiences in public transport not only for passengers but also for staff providing the service. In the UK, the rail industry has been traditionally slow to incorporate innovative technologies. The complexity of the systems that constitutes the railways makes modernisation more difficult (Schmid, 2001; Wilson, 2014), and stakeholders report that the British rail industry lags behind competitors in regards to innovation (Hacktrain, 2016). Studies show that passengers demand more information to be available (Transport Focus, 2014a) and more technologies to be used (Transport Focus, 2014b). It is possible to provide, for example, real-time pre-trip, onboard and post-trip information, and advanced, automated fare collection systems (Camacho et al., 2013; Foth and Schroeter, 2010). There are examples of new 
technology being proposed or implemented, such as navigation and wayfinding aids to improve boarding (L. C. Oliveira et al., 2019; Peña Miñano et al., 2017) and advanced onboard information systems for passengers and crew (Rogers et al., 2014).

However, studies designed specifically to map and improve staff experiences are scarce. Existing research and methods focus on the customer perspective of the user experience (UX), which have been previously well documented in the literature, for example via customer journey maps (Jüttner et al., 2013; Tseng et al., 1999). Working to improve the customer experience may indirectly improve the work quality for employees (Johnston and Kong, 2011), but staff experiences are rarely studied. Front line employees engage directly with customers and this process can represent a positive emotional engagement, but at times can be emotionally demanding for staff (Maria Stock et al., 2017). Onboard crew members are often subject to abuse from passengers (Salomonson and Fellesson, 2014), which can affect health and reduce job satisfaction (Boyd, 2002). Furthermore, the railways can be a stressful and traumatic environment for work due to a range of factors such as the risk of incidents (Queirós et al., 2014) and fatalities (Ryan et al., 2018). It is important to understand when and why these negative and positive experiences occur in order to evaluate the opportunities to improve experiences.

\subsection{Experiences}

The introduction of an information support system can increase the capacity and efficiency of people and systems, as long as developed after "solid cooperation between the developers and end users of the system" (Kasvi et al., 2000). User research can provide an understanding of potential challenges and address those that could prevent the smooth adoption of such systems (Dawson et al., 2017). User-centred design is particularly important when designing systems to be introduced for users working on environments where safety is critical (Costa et al., 2017; Sætren et al., 2016).

Experience can be defined as an episode or a length of time that one individual goes through (Hassenzahl, 2010), involving tangible perceptions through the senses and also feelings and thoughts. UX it is a very personal phenomenon: what engages and enchants one user may bore or irritate another (Blythe et al., 2006). UX is fundamentally a subjective judgement, dependent on users' moods, needs, expectations, time, place and social context (Forlizzi and Battarbee, 2004; Hassenzahl and Tractinsky, 2006). Jüttner et al. (2013) add that UX comprises emotional and cognitive aspects since experiences are formed through the contact with stimuli, which trigger an individual to perceive them as good or bad, and to relate them to previous experiences as better or worse.

Interactive products and services that we encounter in our lives also have the power to shape what we feel, and will inevitably influence our experience (Hassenzahl et al., 2010). Whilst a usability approach puts emphasis on efficiency to guarantee that interactions are error-free and fast, an experience approach advocates that interactions should be worthwhile and valuable (Hassenzahl, 
2010). Designers have the responsibility to ensure that the interactions they create will benefit users, in terms of not only efficiency but also people's wellbeing. It is possible to design for pleasurable interactions, to improve experiences and to promote the introduction of "technology as a possibility to improve life directly rather than as a mere tool to solve problems" (Desmet and Hassenzahl, 2012).

\subsection{Understanding rail experiences}

Human factors and ergonomics are often used to understand rail staff activities, the environment they work in and the time pressures they experience (Shepherd and Marshall, 2005). One common observational method is shadowing, when the researcher investigates the activities that individuals perform in their real contexts (Hanington and Martin, 2012; Kuniavsky et al., 2012). Shadowing has been used to evaluate the activities performed by train drivers (Naweed et al., 2018) and the ergonomics of their seats and controls (Nathanael and Marmaras, 2018). Interviewing is another method used with train drivers to understand the details of work routines and produce task diagrams (Naweed, 2014) or evaluate the introduction of new technology (Naweed and Rose, 2018).

One common way to visualise UX is through the design of Customer Journey Maps, which are graphical representations of one's encounters with the products, services or systems. These diagrams usually contain different stages of the journey, user actions and emotions (Stickdorn and Schneider, 2010; Williamson, 2016). The map displays the 'touchpoints' between the user and the system, defined as a point in space and time where some sort of interaction took place. In transport studies, journey maps have been used to illustrate the problematic touchpoints for bus (Aceves-González, 2014) and rail passengers (Oliveira et al., 2017; van Hagen and Bron, 2014). However, no studies were found reporting experiences or analysing tasks performed by customer-facing crew.

\subsection{Aim}

The aim of this research is to provide an assessment of the negative and positive aspects of work routines in order to inform the design of innovative technologies that could be adopted by the rail industry. A crew experience journey map was developed as part of a wider research project investigating the potential for new technologies to improve ergonomics and experiences for rail crew.

The research questions that set the basis for this work were: How do train crew experience their current work routines? What are the negative and positive touchpoints along their journeys? What is the potential for technology to improve their work ergonomics and experiences?

This article answers these questions by reporting on a study that involved interviews and in-the-field observations to understand and describe rail crew experiences. This paper presents key lessons from the user research, which indicates the requirements of innovative technology for rail and potentially for other transport systems. 


\section{Methodology}

Two user studies were designed to answer the research questions proposed above using quantitative and qualitative methods to provide the data required. Two separate methods were used: in-depth semistructured interviews and shadowing, described below. During the interviews, participants reported significant occurrences and issues during the interaction with the rail system (Stein and Ramaseshan, 2016) and the sequential incidents of the interaction (Jüttner et al., 2013). The shadowing technique and debriefing sessions contributed with details of each activity (Naweed and Rose, 2018; Stanton, 2006) and informed the main touchpoints with the rail system. The user affect at each touchpoint was obtained from the qualitative data analysis and observations. When participants described a task in positive or negative terms, we could infer those as generating the corresponding affects in terms of valence (pleasant/unpleasant) and arousal (activation/deactivation) (Posner et al., 2005; Russell, 1980). Emotions from all participants were averaged and plotted into an experience journey map, similarly to examples in the literature (Aceves-González, 2014; Oliveira et al., 2017; van Hagen and Bron, 2014).

\subsection{Participants}

The recruitment of crew members for interviews and shadowing was undertaken by the management from a large train operating company in the UK. Participation was voluntary and no financial incentives were given. The sample for this research comprised 17 train managers (TMs) (five females) and five customer hosts (CHs) (two females). TMs are the main authority aboard, responsible for safety, dispatching the train, revenue protection and customer care, whereas $\mathrm{CHs}$ are responsible for onboard sales in the buffet and at-seat trolley service. Table 1 shows participants and data points.

\begin{tabular}{l|l|c|c|l}
\hline Method & Location & Participants & $\begin{array}{l}\text { Average duration } \\
\text { per participant } \\
\text { (minutes) }\end{array}$ & Total data points \\
\hline $\begin{array}{l}\text { Interviews } \\
\begin{array}{l}\text { Shadowing and } \\
\text { debriefing } \\
\text { interviews }\end{array}\end{array}$ & $\begin{array}{l}\text { Paddington } \\
\text { station offices }\end{array}$ & $8(5 \mathrm{CH}, 3 \mathrm{TM})$ & 57 & $\begin{array}{l}225 \text { statements } \\
\text { tagged } \\
562 \text { observations } \\
\text { logged }\end{array}$ \\
\hline
\end{tabular}

Table 1 - Participants and data. One of the TMs took part in both studies, being interviewed and shadowed, hence the total number of TMs is 17 and not 18.

\subsection{Interviews}

Face-to-face interviews with eight crew members (5 CHs and $3 \mathrm{TMs}$ ) were performed to understand their routines and their expressions of attitudes, feelings, preferences, needs and behaviours (Table 2). The initial part of the interview used for this study had seven main questions followed by subquestions that could prompt participants to develop their answers in relation to the current train systems. Questions tapped into their daily activities and scenarios, which tools and technology they 
used, their challenges in performing the job, how they deal with specific tasks such as seat reservation or revenue protection, and the parts of the work that they enjoy most and least.

The interviewer then presented possible technological innovations that could be implemented for the rail industry. This demonstration was delivered via a PowerPoint presentation on a laptop screen containing diagrams of the proposed systems. Smartphone applications, onboard hardware such as seat occupancy sensors, ticket readers, train communications and online servers could be combined to provide wayfinding, dynamic seat reservation and automatic ticket validation. If implemented, these proposed systems are likely to change some of the work activities on board trains. For example, crew members could have a phone or tablet application to see in real time a diagram of the train with occupancy levels and reservations. Passengers could validate tickets electronically on their seats, and this information would be displayed on crew apps, so they would not need to inspect tickets from these passengers. After this presentation, a set of nine questions and four sub-questions was presented to obtain participants' impressions related to these systems and foster discussion.

A total of 7 hours and 15 minutes were spent interviewing participants, an average of 57 minutes per interviewee (Table 1). The interviews were recorded, transcribed and imported into QSR NVivo software for qualitative analysis. This data was subject to thematic analysis (Braun and Clarke, 2006) to facilitate the process of creating meaning from the interviews. During the analysis, all relevant statements from participants were tagged into meaningful units of information, giving 255 tags. These tags were then clustered into four main themes comprising customer interaction, navigation (through stations and on board trains), seat reservation and ticket validation. Under each theme, the statements were separated into positive or negative opinions about the current systems, and into positive and negative perceptions of what could happen after the implementation of the proposed technologies. Themes obtained from participants' responses were merged and ordered indicating their frequency and importance.

Table 2 - Interview questions

\begin{tabular}{|c|c|c|}
\hline Area & Main question & Sub-questions and prompts \\
\hline Setting the scene & What are your daily activities? & $\begin{array}{l}\text { Please describe scenarios for these } \\
\text { activities }\end{array}$ \\
\hline Human interaction & $\begin{array}{l}\text { Who do you work with daily to perform } \\
\text { your job? }\end{array}$ & $\begin{array}{l}\text { How do you work with them? } \\
\text { Do you have to follow any specific } \\
\text { rules/training? }\end{array}$ \\
\hline $\begin{array}{l}\text { Human-computer } \\
\text { interaction }\end{array}$ & $\begin{array}{l}\text { Which tools/technology do you use to } \\
\text { perform your job (if any)? }\end{array}$ & $\begin{array}{l}\text { How / why do you use them? What } \\
\text { works? What doesn't? }\end{array}$ \\
\hline Challenges & $\begin{array}{l}\text { What are the challenges in performing } \\
\text { your daily job? }\end{array}$ & \\
\hline Seat reservation & $\begin{array}{l}\text { What challenges do you have to deal } \\
\text { with around seat reservations? }\end{array}$ & $\begin{array}{l}\text { Are these affected by the type of the } \\
\text { service (no. of coaches, size, design of } \\
\text { seats, onboard tech?) Nature of the service } \\
\text { (direct, slow train?) Time of the day (peak } \\
\text { / off-peak?) Seasonal fluctuations } \\
\text { (holidays, seasons?) }\end{array}$ \\
\hline
\end{tabular}


Ticket validation

What challenges do you have to deal with around checking tickets?
What aspects of the current systems work well? Why? What could be improved? What do you perceive to be the customers' issues with this system?

Do you observe different issues for different types of customers?

Are these affected by the type of the service (no. of coaches, size, design of seats, onboard tech?) Nature of the service (direct, slow train?) Time of the day (peak / off-peak?) Seasonal fluctuations (holidays, seasons?)

What aspects of the current systems work well? Why? What could be improved? What do you perceive to be the customers' issues with this system?

Do you observe different issues for different types of customers?

Work experience What is the part of the work that you Why? enjoy most / least?

\begin{tabular}{lll} 
(Show presentation about proposed technology) & \\
\hline Work fit & How do you think this project might help & \\
& your daily work? & How do you see a system like this \\
Positives and & What do you like about the project? & working in future? \\
negatives & What problems do you see? & \\
Closing remarks & Is there anything else we should know? & \\
\hline
\end{tabular}

\subsection{Shadowing}

During the present study, quantitative data was obtained by shadowing train crew at their places of work. All train managers were familiar with shadowing and had done it themselves because it is part of the training process to learn their job. The researcher boarded regular train services and followed the TM on their assigned journeys. Participants were recruited on the spot, with the train service being selected at random at the departure station, comprising a variety of daytime and evening intercity services. The selected journeys were between London and locations in the South and West England and Wales.

A simplified task analysis (based on Stanton, 2006) was used to assess the tasks performed in context. Instead of observing one specific task in detail, the researcher registered all major tasks performed by TMs during a train journey. This simplification was needed due to the dynamic aspect of TM's roles, and the consequent unpredictable pace of the shadowing activity. The intention was to obtain as much information about as many activities as possible in this scenario.

A notes sheet was used on a clipboard where the researcher took note of the activities observed. The guiding item of the notes sheet was the time of occurrence, registered as hour:minute at the beginning of the activity. Then, the researcher noted what the TM was doing, and where it took place. If relevant and time permitting, additional information was registered such as how / with whom / with what / why. When that activity finished or when a different one started, a new timestamp was added to the sheet. This method allowed registering a broad range of activities and the calculation of their 
durations, which was later condensed and categorised into a list of major work tasks presented in Table 3. The notes sheet was designed for inputting one activity at a time, but we acknowledge that activities may have overlapped occasionally. We registered a task where most of the attention was focused at each specific time. For example, if when selling tickets a TM started giving information to that passenger whilst processing the ticket, the second activity would take priority as if the first had finished. Photos were taken to illustrate behaviours and tasks during train journeys.

TMs were later debriefed and questioned about the key issues observed during the work activity. The questions used were open-ended, related to the observations for that specific participant and tapped on issues just witnessed, therefore formulated at the spot. For example, the researcher would ask "I noticed that you were using a pen to mark the checked tickets, why is that?" TMs were asked to describe how frequent these issues were, how these situations affect their work, and how they feel when these issues arise. The debriefing happened towards the end of journeys. The location of these sessions varied according to participants' suggestions. Some TMs preferred to stay in a specific 'booth', usually located in coach A, while others invited the researcher to the first class coach, if there was a table available. TMs were also keen to chat during downtimes and breaks. One debriefing session happened on a platform bridge after the end of the journey. The researcher took notes of the answers on a blank sheet of paper given the difficulty to voice record in noisy environments and without a fixed location.

The researcher shadowed 15 TMs in six days of fieldwork. A total of 30 hours and eight minutes on board trains provided 562 observations, and approximately four hours were used for the debriefing sessions. The log sheets were transcribed to MS Excel where data from the observations was subject to quantitative analysis using pivot tables. The number of occurrences of each activity, the time on task and any issues observed in the process were analysed to provide a better understanding of how critical they were.

\section{Results}

Table 3 shows the duration of each activity logged during the shadowing study and the equivalent percentage of time spent on each task. TMs spend most of their time checking tickets (19\% of the journey time), followed by the activity of opening and closing doors at each calling point (17\%). The door procedure was always coupled with announcements before and after each stop (15\%). Customer care took around $14 \%$ of their time, in activities on board trains and at platforms, for example giving information, helping passengers with reduced mobility or allowing passengers to store or retrieve their bikes. Additional safety-related activities included dealing with unattended bags and passengers' unsafe behaviours either on board or on platforms.

\begin{tabular}{lcc}
\hline Activity & $\begin{array}{c}\text { Duration } \\
\text { (hours:minutes) }\end{array}$ & $\%$ \\
\hline
\end{tabular}




\begin{tabular}{lcc}
\hline Checking tickets & $05: 01$ & 19.31 \\
Door procedure & $04: 31$ & 17.38 \\
Announcements & $03: 48$ & 14.62 \\
Customer care & $03: 38$ & 13.98 \\
Selling tickets & $01: 39$ & 6.35 \\
Cashing up & $01: 00$ & 3.85 \\
passenger count & $00: 31$ & 1.99 \\
Safety issues & $00: 21$ & 1.35 \\
Maintenance & $00: 19$ & 1.22 \\
Reservations & $00: 18$ & 1.15 \\
Other (waiting, walking, breaks, & $04: 53$ & 18.79 \\
toilet, chatting with colleagues) & \\
\hline \multicolumn{2}{c}{ Total } & $25: 59$ \\
\hline
\end{tabular}

\subsection{Crew journey experience map}

The crew journey experience map, which resulted from the studies described here, can be seen in Figure 1. On the top of the map, there is the definition of who is represented on the map and who contributed to the information there displayed. The second box of text indicates the scenario to be examined, of what kind of experience is plotted. The user goals are indicated on the right-hand side of the map, and this information is linked to the classification of touchpoints at the bottom of the map. In the centre of the map, the list of activities focuses on the work of train managers given that they have to perform a larger number of tasks and interact more with passengers than customer hosts do. The colour bars at the bottom correspond to the main user goals in each stage of the journey. The bottommost row (in blue) indicates the business goal that the map supports, describing that there are opportunities for new technologies to improve experiences at those specific touchpoints. 

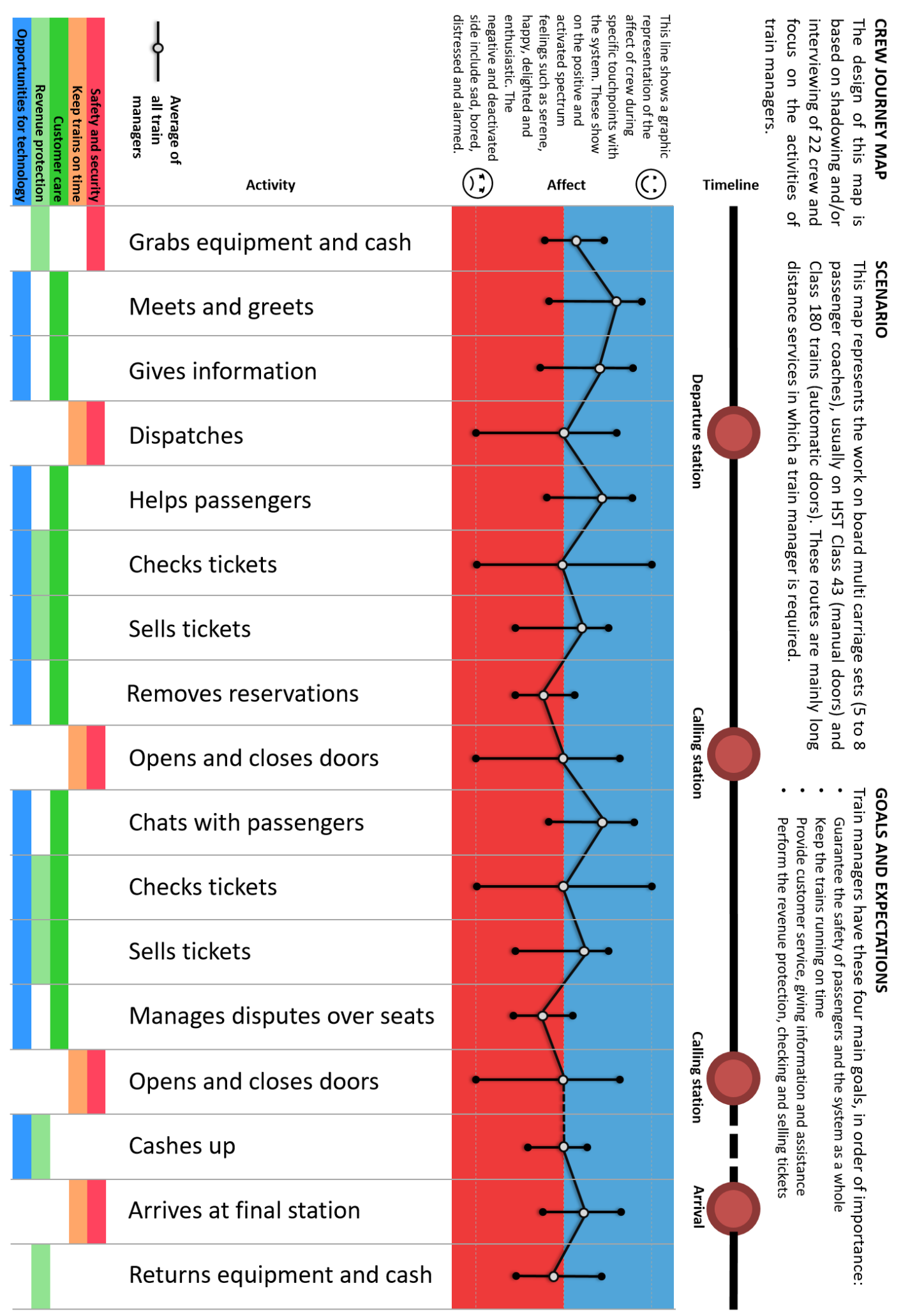


\subsection{Touchpoints}

We describe here the details of the crew journey map (shown in Figure 1), highlighting the key touchpoints in bold. A TM's journey starts when they clock in, check their schedules and get the equipment comprising ticket machines, clippers (to stamp and cancel tickets), high visibility vests, torch, whistle and so on. TMs usually stand at the platform for a few minutes before departure. That is part of their customer service activities when they meet and greet passengers and give information about the destination, calling points and times. Often they know these details, or they consult a printed itinerary for that service, and some of them use their company smartphones to load apps and give further information. This is usually a positive activity, when the TMs feel important and show confidence. Sometimes this can be negative when the assistance that a passenger wants cannot be solved immediately. Crew members reported that the tariff structure is rather complex and the diversity of fares is sometimes challenging even for them to understand, as Participant 2, a customer host [CH2] exemplifies: "we have a lot of questions asked, is this ticket valid, or is that ticket valid?" Participant 1, a train manager [TM1] complements saying that "I sympathise with some of the passengers, it's very difficult to know whether or not your ticket is valid on that train". Often the process of giving information can be repetitive and not particularly nice for crew: "Sometimes there is a queue of people to ask, and passengers all ask the same things" [TM9].

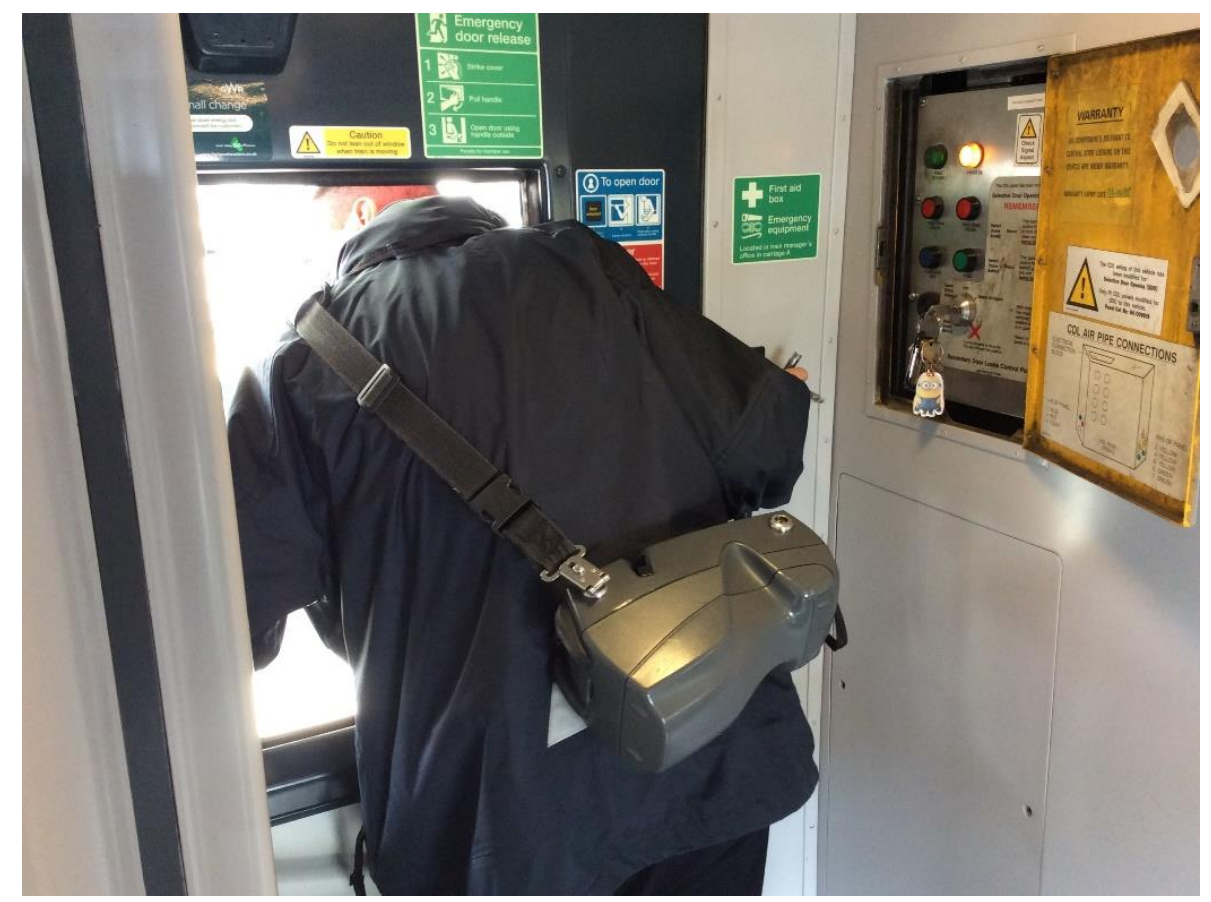

Figure 2 - Train manager checking the platform during departure, on an HST class 43

By the time of departure, the TM is on board the train by the door, checking for last minute passengers intending to catch that train, and ready to dispatch the train (Figure 2). This can be a very stressful situation especially in busy stations and at rush hour, with passengers running down the 
platform, delaying the train or risking an accident. TMs and platform staff have often to shout at people things like 'behind the yellow line' or 'don't touch the train' in order to prevent incidents.

With the train moving, the crew member is happy to help and chat with passengers with diverse activities such as giving information, locating coaches and seats and placing luggage on the overhead racks. During the shadowing study, one TM was seen offering a first-class seat and fetching tea for a passenger in need of extra care. TM7 reported giving similar attention during the interview: "I had a passenger on a journey the other day who was just out of the hospital, and she was very pale, so I made sure she was looked after, she had water, something sweet, I kept attending her to make sure she was $O K$ ". $\mathrm{CH} 2$ illustrates how the customer care activity can be rewarding in itself: "that's nice when someone had some really shitty day and really everything is going against, and you can sort the problem, you can do something good, that's nice as well, makes you feel nice".

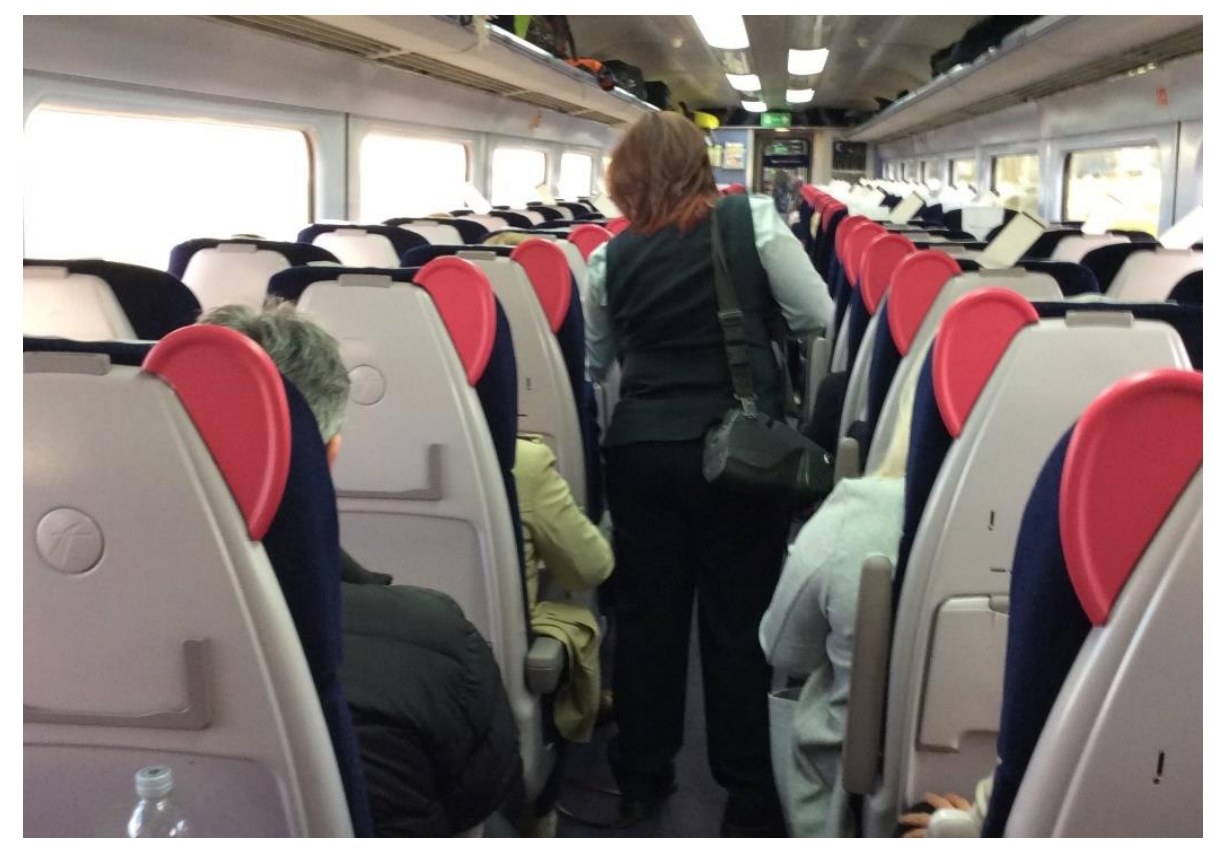

Figure 3 - TM checking tickets on a full coach

The process of checking tickets on board long distance trains is an important part of the revenue protection for companies operating in the UK, to make sure passengers have a valid ticket for their travels. It takes the largest proportion of time during journeys, especially in busy services (Figure 3), taking almost $20 \%$ of TM's time (Table 3). It can be a positive experience, when crew have the chance to interact with passengers. Some TMs were seen checking the destinations on tickets and informing passengers where to change, which platform to go, and even which stairs to use. Some TM were also seen making jokes and laughing with passengers. The possibility of giving assistance, information and care whilst checking tickets is a highly valued activity, as reported by crew. "Most of the times is [spent] doing tickets and making customer service. It's all combined isn't it, it 's checking the tickets, you check if the customer is OK, they're happy, so you're doing all in one go" [TM5]. 
Checking tickets can sometimes be a negative experience, which TMs would rather not do. The time of the day can affect the dedication to revenue protection, and often they are strategic in order to minimise effort. TM22 described that "in the evening it's harder to validate tickets, passengers are tired and trains are busier". In some routes, there are specific stops notorious for fare evaders. Dealing with someone who refuses to pay can be a challenging situation, as TM3 exemplifies: "I don't want to get slapped, and I don't want to delay the train. So my hands are tied'.' In some occasions, TMs cannot check tickets, such as when the service is crowded with passengers obstructing corridors (Figure 4).

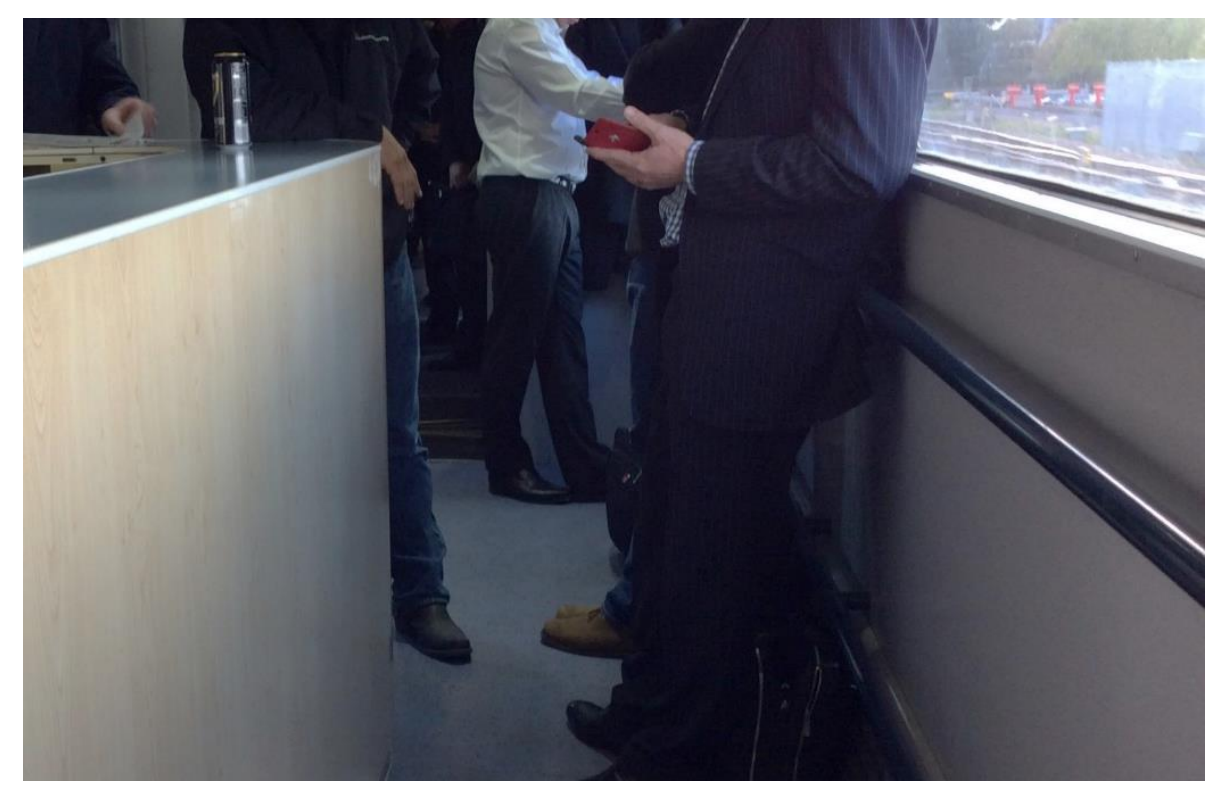

Figure 4 - Crowded service preventing the TM from going through the coaches beyond the buffet car

Revenue protection is a mechanical and repetitive task, as TM15 illustrates: "On trains leaving London, you may have to check 500 to 600 tickets up to Bath" (a 1.5-hour journey). During the ticket validation process, TMs are expected to use clippers, which are a combination of a rubber stamp and a debossing mechanism to prevent ticket reuse. However, these devices were not being used by nine of the 15 participants shadowed. Their explanations ranged from clippers running out of ink, having too much ink and leaving a blot on tickets, inconvenience, being lost or giving injury, as explained by TM5: “Because I've been doing this for a long long time, I've got like a repetitive strain injury whilst marking... So my boss let me write [with a pen], and mark it. Bless him, very kind man". 


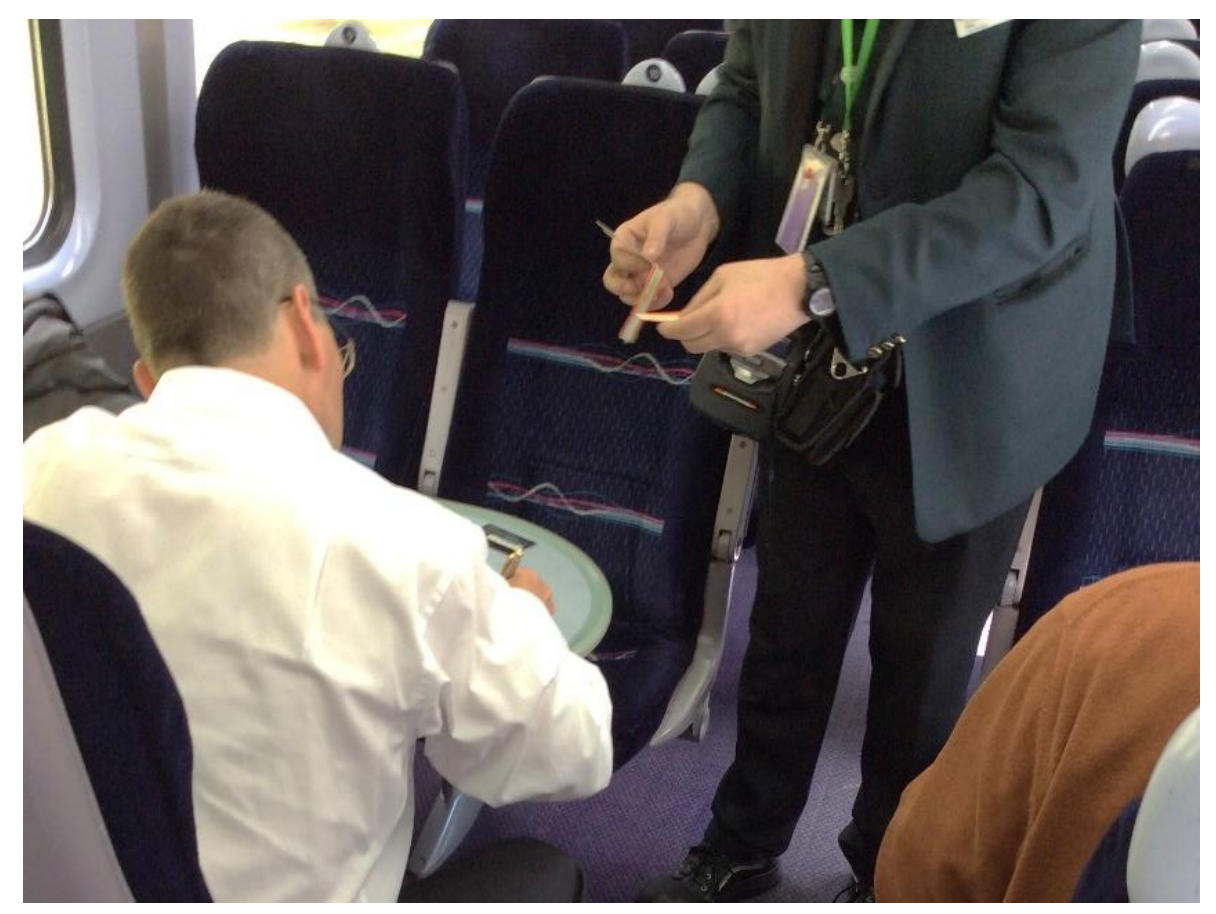

Figure 5 - Passenger signing the sale counterpart

TMs also sell tickets and can earn 5\% of their monthly sales, after a $£ 1000$ threshold. Some reported gains of $£ 400$ on top of their salaries. The possibility of monetary gains makes the process of selling tickets usually positive. However, sometimes it is a time-consuming procedure given that the current machines are not contactless, and that chip and pin devices are sometimes out of order, requiring the swipe and sign method (Figure 5). "We're not even online. We ask them to sign, and check the signature on the back of the card. Now there are just touching cards, contactless, but here we still use to sign. They need to keep up with technology" [CH6]. 


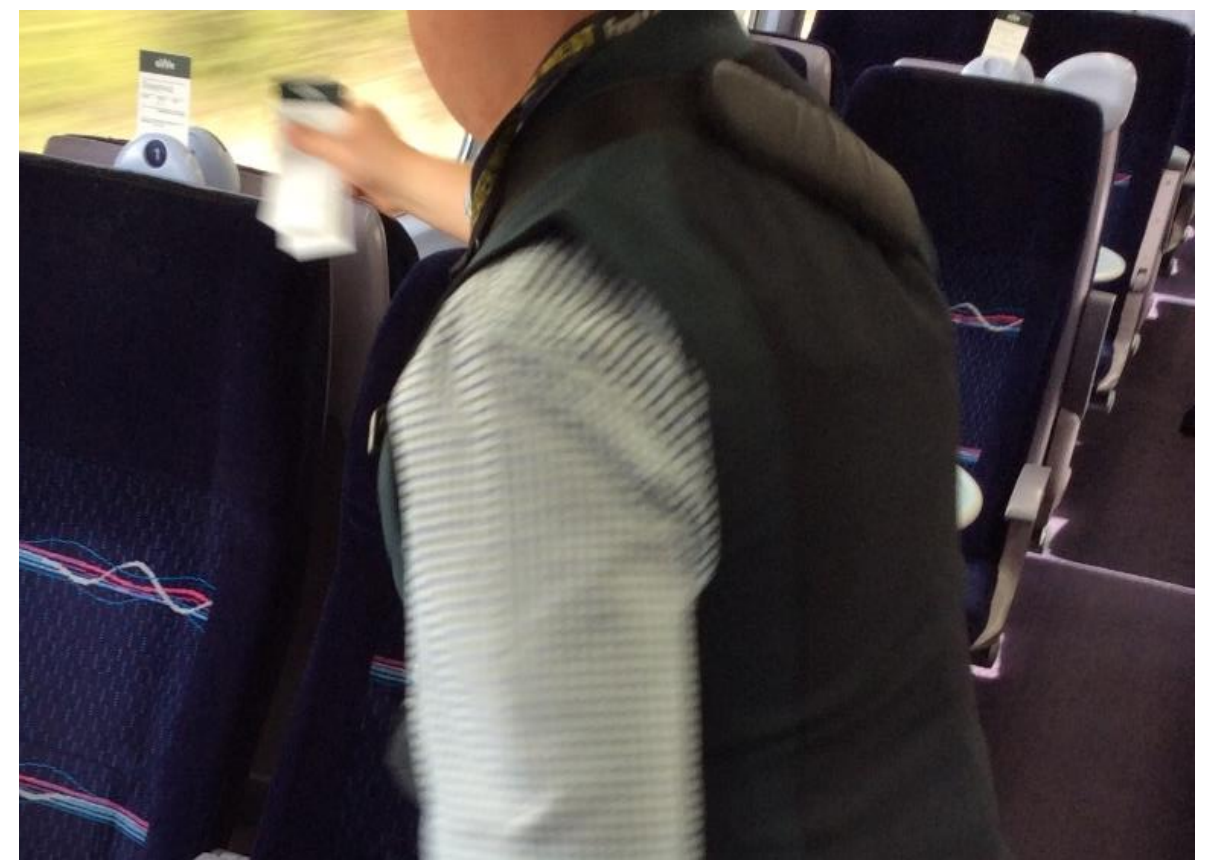

Figure 6 - TM removing unused reservations en route

Often passengers do not show up on the reserved service or decide to sit elsewhere. Sometimes crew remove unused reservations if they see that they are for stations they have already been to (Figure 6). Very rarely crew have to manage disputes over seats, checking passengers' tickets and asking them to give the seat back to whom it belongs. However, in busy services, during a disruption or if the reservations are not in place, it can be stressful for crew. TM1 exemplified: "I had a busy train where passengers had been arguing with each other because they've booked a seat and the reservation labels had not been put up... you have to cancel reservations, and that just caused the worst train nightmare". TM3 reinforced the need for a system to be in good working order: "The reservation system is rendered pointless when it doesn't work... So when it works it is good, when it doesn't it makes things twice as bad as no system at all". 


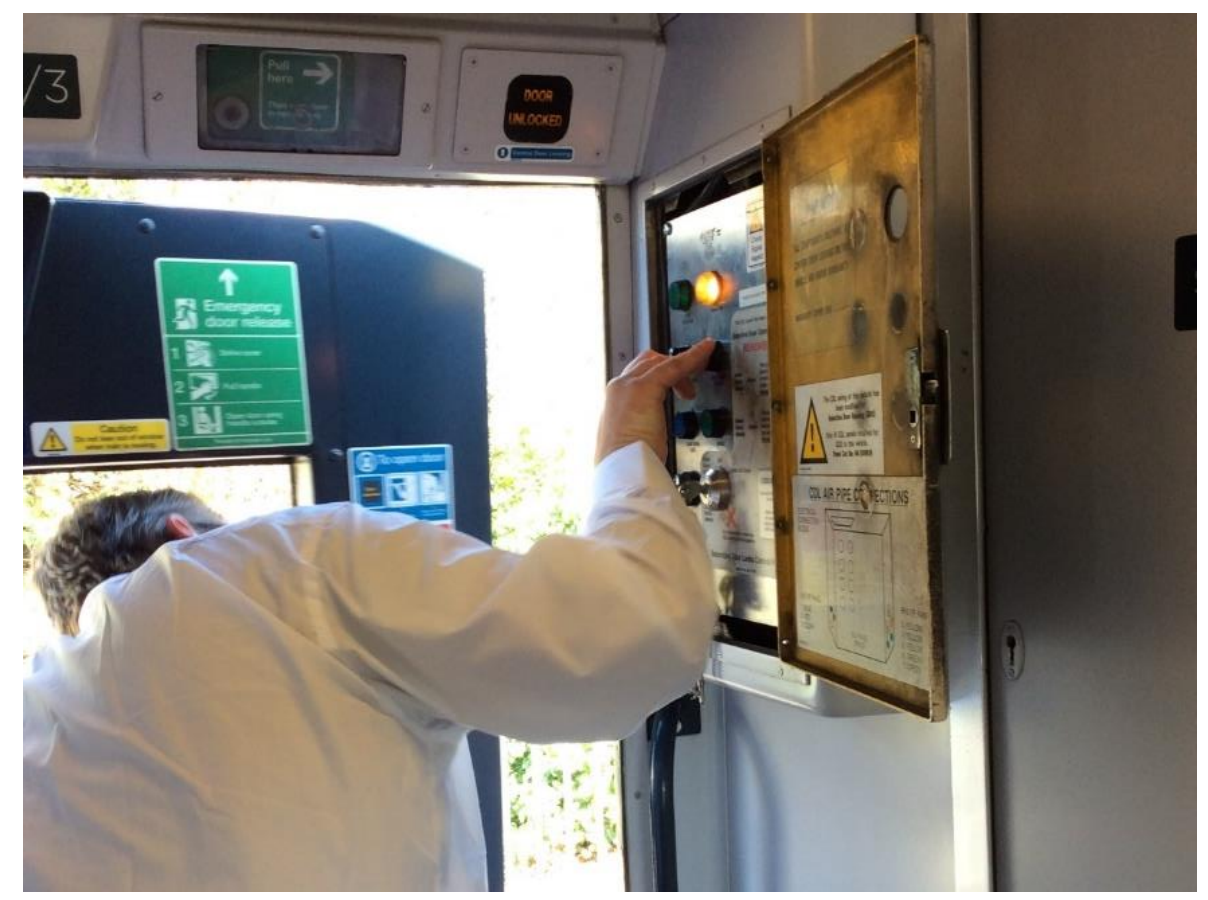

Figure 7 - TM signalling to the driver and opening the door

On the approach to each calling station, the TM has to perform the door procedure (Figure 7) consisting of approximately 20 steps, including announcement, communication with the train conductor via the control panel buzzers, unlocking doors, walking down the platform and doing specific hand gestures and whistle signals. This process is even more complicated at stations with short platforms or without platform staff. It can be stressful given its complexity and coupled with the fact that passengers' behaviour can cause delays and raise safety alerts. In addition, the procedure was performed up to 16 times on a single journey [TM10] and varied with train characteristics.

Crew also take breaks to chat with colleagues, have tea or coffee, and go to the toilet. On the approach to the final destination, TMs can sometimes start cashing up, then report sales on a hard copy of a specific spreadsheet, and prepare to return the equipment and cash to the station office.

\section{Discussion}

Train staff have positive and negative experiences during work, as illustrated by the crew journey experience mapping (Figure 1). Depending on the scenario, a Train Manager (TM) can be positive, happy and excited by their activities during the interaction with the systems and with passengers. In other situations, the tasks may seem negative, sad and stressful, hindering the experience. The mapping of crew experiences provided interesting insights into where the pinch points are.

The current research provides some insights into how technology can improve future journeys towards more pleasurable work activities for train crew. The first highly negative touchpoint on 
crew's journey is the process of dispatching the train from the departure station, and similar experiences repeat at every calling point. The stress was exacerbated by the behaviour of passengers. The time pressures, workload and the risk of accidents increase the tension, as previously reported in the literature (Naweed and Rose, 2018; Schmid, 2001).

Possible ways to minimise these issues could make use of the new technology currently proposed in the literature. The boarding procedure could benefit if users were better informed about platforms, the location of each coach before the train arrives, and the load of coaches in real time (L. C. Oliveira et al., 2019; Rogers et al., 2014). If a technological system informs passengers of the right place to stand on the platform, it could improve the boarding process, distribute the load and therefore make the activity a better experience for both passengers and crew. Furthermore, if a system provides information about occupancy, the number of passengers boarding or alighting, and a list of origins and destinations, it may be possible for crew to tailor the announcements and give more attention to these critical points, therefore potentially making the process run more smoothly.

We observed that the next negative touchpoint for crew is when TMs have to check or sell tickets. They report it to be a time consuming, repetitive, and physically demanding activity. Resonating previous research (Boyd, 2002), we observed that occasionally TMs had their onboard experiences worsened by conflicts with passengers.

Technology can make it possible to integrate the purchase information with the seat occupation, and train passengers may be able to 'check-in' at their seats (Camacho et al., 2013; L. Oliveira et al., 2019). If crew members can be informed of who already have a valid ticket, it will reduce the need for the repetitive task of checking valid tickets, focusing on the priorities such as safety, keeping the train on time and doing customer service. That may also reduce the risks of repetitive strain injury.

However, the interaction with passengers was seen as positive in some occasions. Crew feel valued when they can give assistance, interact with passengers, make jokes and engage emotionally in their job, which can help to replenish their emotional energy (Maria Stock et al., 2017). Furthermore, during the interviews, some TMs demonstrated being reluctant to reduce their role in checking tickets because that is an important opportunity for customer care, especially for less knowledgeable or vulnerable passengers.

Our results indicate that a better way to design this technology would be to highlight passengers who are travelling on that service for the first time, passengers with complex connections or others who may need assistance or information. That would represent a shift from a perceived adversarial role of revenue protection to enhancing the customer experience, with the potential to reduce crew-passenger conflicts. Finally, by indicating which passengers do not have a ticket, TMs can optimise the procedure of selling them. It can increase their commissions and give more time to deal with passengers without means (or intention) to pay. 
Sometimes crew have to manage reservations and mediate a dispute over seats. Preferences regarding seats are very personal and passengers may want to change seats due to the other passengers aboard that carriage (Wardman and Murphy, 2015). An electronic system that automatically reduces the effort in dealing with reservations can improve the work experience for TMs. A dynamic reservation system can allow passengers to reserve a seat in real time, change current reservations and free up a previously allocated seat. However, technology may not prevent people from seating in a reserved seat deliberately and will not solve the problem of overcrowded trains, which are still demanding situations for TMs.

\subsection{Contribution}

This study presented is the first (within mainstream published literature) to understand and capture customer-facing train crew experience through the use of a journey map, which details the positive and negative aspects of their work routines. Previous research tends to focus on customer journey maps to understand clients' satisfaction with products and services (Johnston and Kong, 2011). The train operating company partner in this project will benefit from this information in the process of reviewing current procedures and training staff. The crew map is also being shared with project partners to guide the development of future technologies with the potential to improve work experiences for train crew. Employers must focus on enhancing experiences and at the same time avoid removing valued or enjoyable tasks. By doing so, it will increase the chances of technology acceptance by crew.

Established methods of Human Factors and Ergonomics are currently used on the railways, mainly to tackle the safety challenges (Hignett et al., 2018) or to modify and improve current systems (Wilson, 2014). The journey map presented here demonstrates the need for further exploration by giving an account of the negative and positive touchpoints with the system. This work adds a perspective of crew experience and wellbeing, which is often neglected in work environments such as trains and aeroplanes (Boyd, 2002; Maria Stock et al., 2017).

A number of contributions are drawn from this research, indicating the potential for improving experiences via the introduction of innovative technology. The crew experience journey map (Figure 1) indicates that the opportunities for technology are not directly related to instances crucial for safety and timeliness, e.g. dispatching the train or opening and closing doors. The suggested features focus more on improving customer care and revenue protection, since these were the original targets of the proposed technology. However, improving crew and customer journey experiences could also deliver positive consequences to the safety and efficiency of the whole system, as described below:

- Crew want the trains to be safe. Many safety incidents are caused by passengers' behaviour at the platform-train interface. Therefore, crew are likely to embrace a system that makes passengers behave more safely. 
- A system could indicate departure times, the location of the train, the right place to stand on the platform to find a seat, and the available options such as a later, less crowded or cheaper train. This information could reduce the chances of passengers being involved in accidents.

- Crew want the trains to be on time. Delays are often caused by crowding, which increases the boarding and alighting times. Often, one end of the train is crowded and the other is empty. Crew are likely to embrace a system that helps trains run on time.

- A system could indicate occupancy levels on specific carriages in order to influence passengers' behaviours at stations. With real-time information, passengers may be distributed more evenly along the platform and therefore reduce dwell times.

- Crew enjoy providing customer care, and there are often less experienced and vulnerable passengers aboard trains. Crew are likely to embrace a system that reduces the mechanical work of checking valid tickets and eliminates the need to interrupt passengers who do not want interaction.

- A system could provide a way to separate those who have tickets and are experienced with the train service from those who are not, freeing time for crew to dedicate attention to those in need of assistance.

- Train crew earn a commission from selling tickets aboard. Sometimes they cannot check all tickets due to not having enough time, therefore losing potential sales. Crew are likely to embrace a system that helps them selling more tickets and earning more commission.

○ A system could free up time from checking valid tickets and indicate passengers without a valid ticket for that journey.

\subsection{Limitations and future work}

This research presented a number of limitations, which are listed below. Mitigation measures were in place whenever possible, and we believe that those limitations were addressed as well as was reasonable. During the shadowing activity, the note sheets allowed the capture of observable activities only. Task analysis has been used to analyse information flow and produce more complex diagrams including decision-making processes (Stanton, 2006). In addition, when participants have the time to stop, analyse and discuss their emotions at each touchpoint, they may come with more accurate representations of affect (van Hagen and Bron, 2014). However, our study was designed to observe crew in their real contexts. To explore these underlying issues, the debriefing sessions were used alongside the observations and allow for data triangulation.

The fieldwork reported here was conducted by one researcher only, coding the observations on paper as the subject participants performed their work activities. Video recordings could be used (Nathanael and Marmaras, 2018) to allow more than one researcher to conduct independent analyses of the data 
(Kazmierczak et al., 2005). However, this method may generate other challenges regarding image quality and passenger privacy.

It is understood that qualitative data analysis can be subjective and down to the interpretation of the researchers and the subtleties of the English language (Long and Johnson, 2000). Here, we took speech and actions and converted them into a smiley faces scale to generate the emotional curve displayed in the experience map. It has been a challenge to understand the underlying emotional estates related to safety-critical work such as the railways (McLeod et al., 2005). To minimise subjectivity, part of the data was examined by a second researcher to provide a cross-researcher reliability.

Finally, our participants were working for a specific company operating in the South and West England and Wales. Therefore, we understand that the crew experience map presented here may not be representative of the overall workforce on board trains in the UK, and further research is required to refine and validate it.

Practitioners can use the current journey map to design better work activities for rail crew, having as a starting point a broader view of the systemic and holistic aspects of the railways (Wilson, 2014). Subsequent research could then take specific touchpoints and evaluate them in more detail, for example using hierarchical task analysis of specific activities (Rose and Bearman, 2012; Stanton, 2006). Studies can also assess the impact of technology on these experiences via working prototypes of the systems in a real or simulated context of use. A further useful next step could be to overlay crew maps with customer maps to evaluate where the problematic touchpoints are - where experiences are negative for both, this indicates a real opportunity for improvement.

\section{Conclusion}

This study shed light onto the work performed by onboard crew, indicating how positively or negatively they view it at different points of interaction during train journeys. The crew experience map describes the touchpoints with the rail system and with passengers, highlighting the critical, positive and negative aspects of the journeys. The current research matched this new knowledge with the possibility of introducing new technology to improve crew journey experiences.

The results provide indications of the fit between technology and the work conducted by train managers, and at the same time offer insights into the challenges that changes in these systems may introduce. There is potential for improving work routines, but it is important to analyse each touchpoint with the rail system and the corresponding experiences in detail. Future technology may be able to eliminate some repetitive or unpleasant tasks such as checking valid tickets and minimise risks during boarding and alighting, but should not remove enjoyable parts of current journeys, for example, the interaction with passengers. 


\section{Acknowledgements}

This research is performed as part of the "CLoSeR: Customer Loyalty and Dynamic Seat Reservation System" project, funded by RSSB / Innovate UK (Grant No 102483). This project was selected through the competition 'Enhancing Customer Experience in Rail'. The research obtained full ethics approval from the Biomedical \& Scientific Research Ethics Committee - University of Warwick (code REGO-2016-1771).

\section{References}

Aceves-González, C., 2014. The application and development of inclusive service design in the context of a bus service. Loughborough University.

Blythe, M., Reid, J., Wright, P., Geelhoed, E., 2006. Interdisciplinary criticism: Analysing the experience of riot! a location-sensitive digital narrative. Behav. Inf. Technol. 25, 127-139. doi:10.1080/01449290500331131

Boyd, C., 2002. Customer Violence and Employee Health and Safety. Work. Employ. Soc. 16, 151169. doi:10.1177/09500170222119290

Braun, V., Clarke, V., 2006. Using thematic analysis in psychology. Qual. Res. Psychol. 3, 77-101. doi:10.1191/1478088706qp063oa

Camacho, T.D., Foth, M., Rakotonirainy, A., 2013. Pervasive Technology and Public Transport: Opportunities Beyond Telematics. IEEE Pervasive Comput. 12, 18-25. doi:10.1109/MPRV.2012.61

Costa, N.A., Holder, E., MacKinnon, S.N., 2017. Implementing human centred design in the context of a graphical user interface redesign for ship manoeuvring. Int. J. Hum. Comput. Stud. 100, 5565. doi:10.1016/j.ijhcs.2016.12.006

Dawson, C.H., Mackrill, J., Cain, R., 2017. Assessing user acceptance towards automated and conventional sink use for hand decontamination using the technology acceptance model. Ergonomics 1-13. doi:10.1080/00140139.2017.1316018

Desmet, P., Hassenzahl, M., 2012. Towards happiness: Possibility-driven design, in: Zacarias, M., de Oliveira, J.V. (Eds.), Human-Computer Interaction: The Agency Perspective. Springer International Publishing, pp. 3-27.

Forlizzi, J., Battarbee, K., 2004. Understanding experience in interactive systems, in: Proceedings of the 2004 Conference on Designing Interactive Systems Processes, Practices, Methods, and Techniques - DIS '04. ACM Press, New York, New York, USA, p. 261. doi:10.1145/1013115.1013152

Foth, M., Schroeter, R., 2010. Enhancing the experience of public transport users with urban screens and mobile applications. Proc. 14th Int. Acad. MindTrek Conf. Envisioning Futur. Media Environ. - MindTrek '10 33. doi:10.1145/1930488.1930496

Hacktrain, 2016. B.A.R.R.I.E.R.S REPORT - Bringing Actionable Recommendations to Revitalise Innovation and Entrepreneurship in the Rail Sector Report [WWW Document]. URL https://railway-news.com/barriers-report/ (accessed 4.5.17).

Hanington, B., Martin, B., 2012. Universal Methods of Design: 100 Ways to Research Complex Problems, Develop Innovative Ideas, and Design Effective Solutions. Rockport Publishers.

Hassenzahl, M., 2010. Experience Design: Technology for All the Right Reasons. Synth. Lect. Human-Centered Informatics 3, 1-95. doi:10.2200/S00261ED1V01 Y201003HCI008

Hassenzahl, M., Diefenbach, S., Göritz, A., 2010. Needs, affect, and interactive products - Facets of user experience. Interact. Comput. 22, 353-362. doi:10.1016/j.intcom.2010.04.002

Hassenzahl, M., Tractinsky, N., 2006. User experience - A research agenda. Behav. Inf. Technol. 25, 91-97. doi:10.1080/01449290500330331

Hignett, S., Lang, A., Pickup, L., Ives, C., Fray, M., McKeown, C., Tapley, S., Woodward, M., Bowie, P., 2018. More holes than cheese. What prevents the delivery of effective, high quality and safe health care in England? Ergonomics 61, 5-14. doi:10.1080/00140139.2016.1245446

Johnston, R., Kong, X., 2011. The customer experience: a road-map for improvement. Manag. Serv. 
Qual. An Int. J. 21, 5-24. doi:10.1108/09604521111100225

Jüttner, U., Schaffner, D., Windler, K., Maklan, S., 2013. Customer - service experiences: Developing and applying a sequential incident laddering technique. Eur. J. Mark. 47, 738-769. doi:10.1108/03090561311306769

Kasvi, J.J.J., Vartiainen, M., Pulkkis, A., Nieminen, M., 2000. The role of information support systems in the joint optimization of work systems. Hum. Factors Ergon. Manuf. 10, 193-221. doi:10.1002/(SICI)1520-6564(200021)10:2<193::AID-HFM5>3.0.CO;2-H

Kazmierczak, K., Mathiassen, S.E., Forsman, M., Winkel, J., 2005. An integrated analysis of ergonomics and time consumption in Swedish "craft-type" car disassembly. Appl. Ergon. 36, 263-273. doi:10.1016/j.apergo.2005.01.010

Kuniavsky, M., Goodman, E., Moed, A., 2012. Observing the User Experience: A Practitioner's Guide to User Research, 2nd ed. Morgan Kaufmann.

Long, T., Johnson, M., 2000. Rigour, reliability and validity in qualitative research. Clin. Eff. Nurs. 4, 30-37. doi:10.1054/cein.2000.0106

Maria Stock, R., de Jong, A., Zacharias, N.A., Stock, R.M., Jong, A. de, Zacharias, N.A., 2017. Frontline Employees' Innovative Service Behavior as Key to Customer Loyalty: Insights into FLEs' Resource Gain Spiral. J. Prod. Innov. Manag. 34, 223-245. doi:10.1111/jpim.12338

McLeod, R.W., Walker, G.H., Moray, N., 2005. Analysing and modelling train driver performance. Appl. Ergon. 36, 671-680. doi:10.1016/j.apergo.2005.05.006

Nathanael, D., Marmaras, N., 2018. From the seat to the system: Re-designing a tram drivers' workstation combining technical and contextual aspects. Appl. Ergon. 73, 214-226. doi:10.1016/j.apergo.2018.07.013

Naweed, A., 2014. Investigations into the skills of modern and traditional train driving. Appl. Ergon. 45, 462-470. doi:10.1016/j.apergo.2013.06.006

Naweed, A., Balakrishnan, G., Dorrian, J., 2018. Going solo: Hierarchical task analysis of the second driver in "two-up" (multi-person) freight rail operations. Appl. Ergon. 70, 202-231. doi:10.1016/j.apergo.2018.01.002

Naweed, A., Rose, J., 2018. Assessing technology acceptance for skills development and real-world decision-making in the context of train driving. Transp. Res. Part F Traffic Psychol. Behav. 52, 86-100. doi:10.1016/j.trf.2017.11.003

Oliveira, L., Bradley, C., Birrell, S., Davies, A., Tinworth, N., Cain, R., 2017. Understanding passengers' experiences of train journeys to inform the design of technological innovations, in: Re: Research - the 2017 International Association of Societies of Design Research (IASDR) Conference. Cincinnati, Ohio, USA, pp. 838-853. doi:10.7945/C2R388

Oliveira, L., Bruen, C., Birrell, S., Cain, R., 2019. What passengers really want: Assessing the value of rail innovation to improve experiences. Transp. Res. Interdiscip. Perspect. 1, 1-9. doi:10.1016/j.trip.2019.100014

Oliveira, L.C., Fox, C., Birrell, S., Cain, R., 2019. Analysing passengers' behaviours when boarding trains to improve rail infrastructure and technology. Robot. Comput. Integr. Manuf. 57, 282291. doi:10.1016/j.rcim.2018.12.008

Peña Miñano, S., Kirkwood, L., Court, S., Farnsworth, M., Orlovs, I., Shehab, E., Tinworth, N., Miñano, S.P., Kirkwood, L., Court, S., Farnsworth, M., Shehab, E., Tinworth, N., Peña Miñano, S., Kirkwood, L., Court, S., Farnsworth, M., Orlovs, I., Shehab, E., Tinworth, N., 2017. A review of digital wayfinding technologies in the transportation industry, in: Advances in Transdisciplinary Engineering. IOS Press, Greenwich, London, UK, pp. 207-212. doi:10.3233/978-1-61499-792-4-207

Posner, J., Russell, J.A., Peterson, B.S., 2005. The circumplex model of affect: An integrative approach to affective neuroscience, cognitive development, and psychopathology. Dev. Psychopathol. 17, 715-734. doi:10.1017/S0954579405050340

Queirós, C., Fonseca, S., Guimarães, F., Martins, V., 2014. A dimensão do fator humano na segurança ferroviária: estados emocionais do profissional, in: Lourenço, L. (Ed.), Alacafache: 30 Anos Depois. Imprensa da Universidade de Coimbra, Coimbra, Portugal, pp. 33-53. doi:10.14195/978-989-26-1386-4_2

Rogers, A., Robinson, C., Agatsuma, K., Iwasaki, M., Inarida, S., Yamamoto, T., Konishi, K., Mochida, T., Articles, F., 2014. Development of Class 800 / 801 High-speed Rolling Stock for 
UK Intercity Express Programme. Hitachi Rev. 63, 646-654.

Rose, J.A., Bearman, C., 2012. Making effective use of task analysis to identify human factors issues in new rail technology. Appl. Ergon. 43, 614-624. doi:10.1016/j.apergo.2011.09.005

Russell, J.A., 1980. A circumplex model of affect. J. Pers. Soc. Psychol. 39, 1161-1178. doi:10.1037/h0077714

Ryan, B., Kallberg, V.P., Rådbo, H., Havârneanu, G.M., Silla, A., Lukaschek, K., Burkhardt, J.M., Bruyelle, J.L., El-Koursi, E.M., Beurskens, E., Hedqvist, M., 2018. Collecting evidence from distributed sources to evaluate railway suicide and trespass prevention measures. Ergonomics 0 , 1-21. doi:10.1080/00140139.2018.1485970

Sætren, G.B., Hogenboom, S., Laumann, K., 2016. A study of a technological development process: Human factors - the forgotten factors? Cogn. Technol. Work 18, 595-611. doi:10.1007/s10111016-0379-x

Salomonson, N., Fellesson, M., 2014. Tricks and tactics used against troublesome travelers-Frontline staff's experiences from Swedish buses and trains. Res. Transp. Bus. Manag. 10, 53-59. doi:10.1016/j.rtbm.2014.04.002

Schmid, F., 2001. Organisational ergonomics: a case study from the railway systems area, in: People in Control. Human Factors in Control Room Design. Institution of Engineering and Technology, pp. 261-270. doi:10.1049/cp:20010473

Shepherd, A., Marshall, E., 2005. Timeliness and task specification in designing for human factors in railway operations. Appl. Ergon. 36, 719-727. doi:10.1016/j.apergo.2005.05.005

Stanton, N.A., 2006. Hierarchical task analysis: Developments, applications, and extensions. Appl. Ergon. 37, 55-79. doi:10.1016/j.apergo.2005.06.003

Stein, A., Ramaseshan, B., 2016. Towards the identification of customer experience touch point elements. J. Retail. Consum. Serv. 30, 8-19. doi:10.1016/j.jretconser.2015.12.001

Stickdorn, M., Schneider, J., 2010. This is service design thinking. BIS Publishers, Amsterdam, The Netherlands.

Transport Focus, 2014a. Rail passengers' priorities for improvements [WWW Document]. URL https://www.transportfocus.org.uk/research-publications/publications/rail-passengers-prioritiesfor-improvements-october-2014/

Transport Focus, 2014b. The passenger experience - the full research report [WWW Document]. URL http://www.transportfocus.org.uk/research/publications/the-passenger-experience-the-fullresearch-report

Tseng, M.M., Qinhai, M., Su, C., 1999. Mapping customers' service experience for operations improvement. Bus. Process Manag. J. 5, 50-64. doi:10.1108/14637159910249126

van Hagen, M., Bron, P., 2014. Enhancing the Experience of the Train Journey: Changing the Focus from Satisfaction to Emotional Experience of Customers. Transp. Res. Procedia 1, 253-263. doi:10.1016/j.trpro.2014.07.025

Wardman, M., Murphy, P., 2015. Passengers' valuations of train seating layout, position and occupancy. Transp. Res. Part A Policy Pract. 74, 222-238. doi:10.1016/j.tra.2015.01.007

Williamson, K., 2016. When and How to Create Customer Journey Maps [WWW Document]. Nielsen Norman Gr. URL https://www.nngroup.com/articles/customer-journey-mapping/ (accessed 8.2.16).

Wilson, J.R., 2014. Fundamentals of systems ergonomics/human factors. Appl. Ergon. 45, 5-13. doi:10.1016/j.apergo.2013.03.021 